\title{
RNA Polymerase-Associated Protein CTR9 Homolog
}

National Cancer Institute

\section{Source}

National Cancer Institute. RNA Polymerase-Associated Protein CTR9 Homolog. NCI

Thesaurus. Code C118342.

RNA polymerase-associated protein CT R9 homolog (1173 aa, $\sim 134 \mathrm{kDa}$ ) is encoded by the human CT R9 gene. This protein is involved in transcriptional elong ation, histone modification and embryonic stem cell pluripotency. 